\title{
The effect of stress coping on resilience of firefighters.
}

\author{
Sung-Sim Lee ${ }^{1}$, Sookyoung Jeong ${ }^{1}$, Young-Soon Choi ${ }^{2 *}$ \\ ${ }^{1}$ Department of Nursing, Saekyung College, 197, Hasong-Ro, Yeongwol-Eup, Yeongwol-Gun, Gangwon-Do, Republic \\ of Korea \\ ${ }^{2}$ Department of Nursing, College of Health Sciences, Kangwon National University, Hwangjo-Gil, Samcheok-Si, \\ Gangwon-Do, Republic of Korea
}

\begin{abstract}
This study was attempted to provide basic data on mental health by identifying factors affecting the resilience of firefighting officers. The data collection was conducted from May $1^{\text {st }}, 2018$ to May $31^{\text {st }}$, 2018, with the consent of the target person and the questionnaire was conducted. The number of participants used in the final analysis was 147. The questionnaire consisted of demographic characteristics, stress coping, and resilience. The collected data were analysed using SPSS 21.0 statistical program using descriptive statistics, t-test, ANOVA, Pearson's correlation, and Multiplier regression. The results of this study showed that the difference in resilience according to general characteristics was the result of subjective health condition, stress relief method, and subjective health condition in stress coping. Resilience showed a static correlation with stress coping, and stress coping showed a positive correlation between active coping and passive coping. In addition, active coping showed a positive correlation with passive coping. Based on the above results, regression analysis showed that factors affecting resilience were stress coping and subjective health status, and the factors used in the analysis explained $49.2 \%$ of resilience.
\end{abstract}

Keywords: Firefighters, Resilience, Stress, Coping behaviour.

Accepted on February 25, 2019

\section{Introduction}

Firefighters are special civil servants who are responsible for emergency rescue functions at all disaster sites, including fire and human disasters [1]. Regarding the duties of the Ministry of Fire, the Basic Law of Fire Service "protects people's life, body and property through fire prevention, vigilance, suppression, fire, disaster, disaster and other emergency situations, And to contribute to the promotion of welfare" [2].

As a result of various risk factors such as fire, disaster, disaster, rescue and emergency, firefighters are easily fatigued due to psychological and physical stresses arising from special work environment and work besides physical diseases, and stress was felt to be serious, such as excitement or anger at minor things [3].

Lazarus and Falkman defined stress coping as "cognitive and behavioral efforts to reduce or persevere stress and tension", "Cognitive and behavioral efforts to reduce and resolve to understand the inner desire to be an individual assessment that has exceeded the resources or too much emphasis" [4]. Coping is also an all-inclusive response to an individual's stress situation, which includes learned or instinctive responses to inappropriate stimuli. In other words, how individuals cope with stress is influenced by both positive and negative effects on individual growth [5]. The impact of stress on individuals varies depending on personality, personal characteristics, and social support, and if you cope with stress properly, you will learn how to overcome it when stress occurs again [6]. Proper coping with stress is an important factor in improving the quality of life, so it is important to find a stress coping method for each individual [7].

A prior study on the coping of stress by firefighters, firefighters have found that they use a lot of passive coping methods when solving sudden and difficult cases [8]. In addition, in a study of firefighting officers on mental health, it was said that people who use passive coping need mediation to improve active coping because they are unhealthy in terms of mental health rather than those who use active coping [9]. Therefore, firefighters who are in a high stress situation compared to other occupational groups need to know what coping methods are mainly used.

Resilience is the ability to recover from crisis and adversity, to live a more resilient life after overcoming crisis, and it is important to protect the negative effects of stress in the daily life of firefighters with various stresses and to tolerate and respond to persistent stress [10]. 
Resilience was found to be different among individuals, and it was found that people with high resilience showed less posttraumatic symptoms in relation to major events than those with low resilience [11]. In addition to disasters, it was found that people with high resilience also had a high recovery in relation to stress [12].

The Goyumi saw resilience as a function that allows the lost level of adaptation to return and recover due to the stress environment [13], it as a positive force to adapt and overcome adversity and stress environment [14]. Resilience as social psychological ability to cope with personal adversity, adapt to environment, and mental growth ability [15].

It is considered necessary to confirm the important resilience to cope with the stress to the firefighting officers exposed to many stress situations, but there is a lack of prior research on this.

This study confirms the degree of stress coping and resilience of firefighters and confirms the relationship between stress coping style and resilience. In addition, we conducted this study to identify the factors affecting resilience and to use it as basic data to improve the mental health of firefighting officers and to help them find ways to cope with stress.

\section{Research Methodology}

\section{Research design}

This study is a descriptive research using structured questionnaires to investigate the effect of stress coping on the resilience of fire fighter.

\section{Research subjects}

This study was conducted for firefighting officers in G city and $\mathrm{Y}$ city in Gangwondo Province. The purpose of this research was understood and it was conveniently extracted to those who voluntarily agreed to participate in the research.

The number of samples was calculated by using $\mathrm{G}^{*}$ Power 3.1.5 program for multiple regression analysis, the significance level was calculated as .05 , the power was 0.95 , the effect size was 0.15 , and the final sample the size was 146 people. A total of 160 copies were distributed in consideration of the number of dropouts, and 150 copies were collected. Among them, 147 data were used for the final analysis except for 3 cases where the response was insufficient.

\section{Research tools}

Stress coping: Stress coping implies a constantly changing cognitive and behavioral effort to control the external and internal demands that are burdened by the individual or that he or she is considered to transcend resources [4]. It was developed by Lazarus and Falkman [4], and translated by Kim et al. [16] and used by the Bang [17]. This tool consists of active coping (coping with problems and coping with social support) and passive coping (coping with emotions and coping with desires). It was composed of a 5-point Likert scale with totally 24 items. In the study of Bang [17], Cronbach's $\alpha$ value of the active coping style was .82 and the Cronbach's $\alpha$ value of the passive coping style was 0.72 . In this study, the Cronbach's $\alpha$ value of the active coping style was 0.89 and the Cronbach's $\alpha$ value of the passive coping style was 0.83 .

Resilience: Resilience means a combination of capabilities and characteristics that include a process of dynamic interaction, allowing individuals to recover from their original state, adapt successfully, and adapt to their physical condition despite stress or to interact dynamically [18]. It was used what Bae [19] translated the resiliency measurement tool developed by Connor [20] (K-CD-RISC: Korean Connor Da vidson Resilience Scale). The tool consists of five sub-factors: robustness, persistence, optimism, support, and spirituality. It was composed of a 5-point Likert scale with totally 25 items. Cronbach's $\alpha$ value stood at 0.93 . Cronbach's $\alpha$ value in this study came to 0.94 .

\section{Data collection method}

Data collection was made through the one-to-one interview by each individual with a researcher and 3 research assistants, who were trained in advance, from May $1^{\text {st }}, 2018$, to May $31^{\text {st }}$. A structured questionnaire was used in subjects with a written consent of participating in the research. A total of 160 copies were distributed in consideration of the number of dropouts, and 150 copies were collected. Among them, 146 data were used for the final analysis except for 3 cases where the response was insufficient.

\section{Data analysis method}

The collected data are analysed using the SPSS 21.0 program as follows. Resilience and stress coping level, according to the demographic characteristics of the subjects was analysed with descriptive statistics, t-test, ANOVA, and post-test were used for Scheff'e test. The correlations between resilience and stress coping were analysed using Pearson's correlation. The effects of the resilience were analysed by multiple regression.

\section{Results}

\section{Difference in resilience, stress coping of according to general characteristics}

Resilience differences in general characteristics was statistically significant with subjective health state $(F=7.38$, $\mathrm{p}<0.001)$, stress relief $(\mathrm{F}=3.77, \mathrm{p}<0.05)$. Stress coping differences in general characteristics was statistically significant with stress relief $(\mathrm{F}=3.16, \mathrm{p}<0.05)$ (Table 1$)$.

\section{Level of resilience and stress coping}

The resilience was $92.35 \pm 13.82$ on the scale of 125 points. The level of Stress coping was $79.20 \pm 12.01$ on the scale of 120 , in the sub domain, aggressive coping was $41.34 \pm 7.04$ on the scale of 60 , passive coping was $43.60 \pm 5.86$ on the scale of 60 points (Table 2 ). 


\section{Correlation between resilience and stress coping}

The resilience was positively correlated with stress coping $(\mathrm{r}=0.666, \mathrm{p}<0.001)$, Stress coping sub-domain of aggressive coping ( $\mathrm{r}=0.774, \mathrm{p}<0.001)$, and passive coping $(\mathrm{r}=0.429$, $\mathrm{p}<0.001)$. Stress coping showed a significant positive correlation in the aggressive coping $(r=903, p<0.001)$, and passive coping $(r=899, p<0.001)$. Aggressive coping showed a significant positive correlation in the passive coping $(\mathrm{r}=0.631$, $\mathrm{p}<0.001$ ) (Table 3).

\section{Factors affecting resilience}

Before the regression analysis, tolerance and variance inflation factor (VIF) values were examined to see whether multicollinearity occurred between the variables, as a result, the dispersion limit value is greater than 0.1 in both 0.86 to 0.93 , and the dispersion expansion value is 1.07 to 1.17 , there is no problem of multicollinearity. As a result of the multiple regression of the gender, position, subjective health state, stress relief and stress copping, factors affecting resilience the stress relief $(\beta=0.606, p<0.001)$, Subjective health state $(\beta=-0.217$, $\mathrm{p}<0.05$ ) were statistically significant. In particular, the subjective health status was analysed as having a negative effect on the resilience, and the resilience explanatory power of the factors used in the analysis was $49.2 \%$ (Table 4 ).

Table 1. Difference in resilience, stress coping of according to general characteristics $(N=147)$.

\begin{tabular}{|c|c|c|c|c|c|c|}
\hline \multirow[t]{2}{*}{ Characteristics } & \multirow[t]{2}{*}{ Categories } & \multirow[t]{2}{*}{ n (\%) } & \multicolumn{2}{|l|}{ Resilience } & \multicolumn{2}{|l|}{ Stress coping } \\
\hline & & & $M \pm S D$ & t/F (p), Scheffe & $M \pm S D$ & t/F (p), Scheffe \\
\hline \multirow[t]{2}{*}{ Gender } & Male & $134(91.2)$ & $93.01 \pm 13.92$ & $1.87(0.063)$ & $79.56 \pm 11.64$ & $1.17(0.241)$ \\
\hline & Female & $13(8.8)$ & $85.53 \pm 11.08$ & & $75.46 \pm 15.36$ & \\
\hline \multirow[t]{4}{*}{ Age (year) } & $20 \sim 29$ & $20(13.4)$ & $90.90 \pm 16.03$ & $0.46(0.711)$ & $78.85 \pm 13.70$ & $0.29(0.826)$ \\
\hline & $30 \sim 39$ & $54(36.6)$ & $92.11 \pm 14.06$ & & $79.57 \pm 12.17$ & \\
\hline & $40 \sim 49$ & $60(40.7)$ & $92.16 \pm 12.47$ & & $78.43 \pm 10.77$ & \\
\hline & $50 \sim 59$ & $13(9.2)$ & $96.46 \pm 16.09$ & & $81.76 \pm 14.86$ & \\
\hline \multirow[t]{4}{*}{ Education } & High school & $35(23.8)$ & $93.00 \pm 15.75$ & $0.47(0.700)$ & $79.60 \pm 13.63$ & $1.00(0.391)$ \\
\hline & College & $33(22.4)$ & $90.96 \pm 13.97$ & & $77.09 \pm 12.99$ & \\
\hline & University & $77(52.4)$ & $92.89 \pm 12.95$ & & $80.19 \pm 10.80$ & \\
\hline & Graduate school & $2(1.4)$ & $83.00 \pm 14.14$ & & $69.00 \pm 5.65$ & \\
\hline \multirow[t]{2}{*}{ Religion } & Yes & $43(29.3)$ & $92.88 \pm 15.58$ & $0.29(0.765)$ & $80.20 \pm 14.07$ & $0.65(0.516)$ \\
\hline & No & $104(70.7)$ & $92.13 \pm 13.10$ & & $78.78 \pm 11.09$ & \\
\hline \multirow[t]{4}{*}{ Position } & Firemana $^{a}$ & $24(16.3)$ & $86.37 \pm 12.37$ & $2.05(0.109)$ & $76.62 \pm 12.16$ & $1.25(0.292)$ \\
\hline & Semi firefighter ${ }^{\mathrm{b}}$ & $35(24)$ & $95.17 \pm 16.02$ & & $82.40 \pm 13.91$ & \\
\hline & Fire sergeant ${ }^{c}$ & $42(28.8)$ & $92.38 \pm 12.84$ & & $78.95 \pm 10.96$ & \\
\hline & Above fire lieutenant ${ }^{d}$ & $46(30.9)$ & $93.04 \pm 13.12$ & & $78.48 \pm 11.22$ & \\
\hline \multirow[t]{5}{*}{ Subjective health state } & Very healthy ${ }^{a}$ & $21(14.3)$ & $101.42 \pm 10.32$ & $7.38(<.001) a, b>c, d>e$ & $84.86 \pm 17.57$ & $1.51(0.205)$ \\
\hline & General health ${ }^{b}$ & $69(46.9)$ & $94.92 \pm 13.17$ & & $80.20 \pm 17.02$ & \\
\hline & Usuallyc & $36(24.5)$ & $87.00 \pm 14.07$ & & $78.02 \pm 10.24$ & \\
\hline & Slight disease $^{d}$ & $19(12.9)$ & $84.78 \pm 11.40$ & & $77.49 \pm 9.96$ & \\
\hline & Serious disease ${ }^{\mathrm{e}}$ & $2(1.4)$ & $76.50 \pm 4.94$ & & $81.88 \pm 10.75$ & \\
\hline \multirow[t]{4}{*}{ Stress relief } & Talk with colleagues ${ }^{a}$ & $51(34.7)$ & $91.31 \pm 12.56$ & $3.77(0.002)$ & $79.78 \pm 10.26$ & $3.16(0.006)$ \\
\hline & Hobby $^{b}$ & $53(36.1)$ & $96.86 \pm 13.14$ & $e>a, b, d>c, f, g$ & $82.41 \pm 11.39$ & $e>a, b, c, d, f>g$ \\
\hline & Alcohol $^{c}$ & $23(15.6)$ & $87.26 \pm 14.94$ & & $75.26 \pm 13.44$ & \\
\hline & Talk to family ${ }^{d}$ & $7(4.8)$ & $91.00 \pm 14.13$ & & $77.14 \pm 6.46$ & \\
\hline
\end{tabular}




\begin{tabular}{|c|c|c|c|c|c|c|}
\hline & Religious activities ${ }^{\mathrm{e}}$ & $2(1.4)$ & $115.00 \pm 11.31$ & & $87.50 \pm 2.12$ & \\
\hline & Keep in mind ${ }^{f}$ & $5(3.4)$ & $86.40 \pm 8.17$ & & $74.80 \pm 7.88$ & \\
\hline & No solutiong & $6(4.1)$ & $79.83 \pm 11.37$ & & $64.33 \pm 20.20$ & \\
\hline \multirow[t]{2}{*}{ Consider counseling, treatment } & Yes & $23(15.6)$ & $88.65 \pm 12.98$ & $-1.40(0.163)$ & $75.91 \pm 9.91$ & $-1.43(0.153)$ \\
\hline & No & $124(84.4)$ & $93.04 \pm 13.92$ & & $79.81 \pm 12.29$ & \\
\hline
\end{tabular}

Table 2. Level of resilience and stress coping $(n=147)$.

\begin{tabular}{lll}
\hline Variables & Range & M \pm SD \\
\hline Resilience & $25 \sim 125$ & $92.35 \pm 13.82$ \\
\hline Stress coping & $24 \sim 120$ & $79.20 \pm 12.01$ \\
\hline Aggressive coping & $12 \sim 60$ & $41.34 \pm 7.04$ \\
\hline Passive coping & $12 \sim 60$ & $43.60 \pm 5.86$ \\
\hline
\end{tabular}

Table 3. Correlation between resilience and stress coping $(n=147)$.

\begin{tabular}{lllll}
\hline Variables & Resilience & $\begin{array}{l}\text { Stress } \\
\text { coping }\end{array}$ & Aggressive coping Passive coping \\
\hline Resilience & 1 & & & \\
\hline Stress coping & $0.666^{* *}$ & 1 & & \\
\hline $\begin{array}{l}\text { Aggressive } \\
\text { coping }\end{array}$ & $0.774^{* *}$ & $0.903^{* *}$ & 1 & 1 \\
\hline $\begin{array}{l}\text { Passive } \\
\text { coping }\end{array}$ & $0.429^{* *}$ & $0.899^{* *}$ & $0.631^{* *}$ & \\
\hline${ }^{*}<<0.05,{ }^{* *} p<0.001$ & & & \\
\hline
\end{tabular}

Table 4. Factors affecting resilience $(N=147)$.

\begin{tabular}{llllll}
\hline Variables & B & SE & $\boldsymbol{\beta}$ & $\mathbf{t}$ & $\mathbf{p}$ \\
\hline (Constant) & 42.792 & 8.179 & & 5.23 & 0 \\
\hline Stress coping & 0.696 & 0.073 & 0.606 & 9.491 & 0 \\
\hline $\begin{array}{l}\text { Subjective health } \\
\text { state }\end{array}$ & -3.228 & 0.954 & -0.217 & -3.384 & 0.001 \\
\hline $\begin{array}{l}\text { Stress relief } \\
\text { Gender }\end{array}$ & 0.452 & 0.46 & 0.061 & 0.983 & 0.327 \\
\hline Position & -3.116 & 2.977 & -0.064 & -1.047 & 0.297 \\
\hline & 1.509 & 0.793 & 0.117 & 1.903 & 0.059 \\
\hline
\end{tabular}

\section{Discussion}

This study was conducted to identify the effects of stress coping on resilience in G-si, C-si and Y-gun firefighting officers in Gangwon Province.

The results of the study showed that the resilience of firefighters and the coping with stress were positively correlated, and the same results were reported in the study of the effects of resilience on post-traumatic stress symptoms in domestic firefighters [21]. In addition, firefighters reported that mental stress was higher than physical stress [22], and firefighters with severe post-traumatic stress symptoms reported depression and alcohol problems and low resilience [23].

The study found that the methods of relieving stress were in the order of colleagues and stories (34.7\%), hobbies (36.1\%), alcohol $(15.6 \%)$, family stories $(4.8 \%)$, religious activities $(1.4 \%)$, and no solution $(4.1 \%)$. They use relatively positive and positive methods such as talking with colleagues and family, and hobbies, however, $20 \%$ of respondents said that they do not have a solution or solution for drinking, therefore it is necessary to pay attention to the method of relieving the stress of the fire service personnel.

The stress coping methods used to overcome stress situations are problem-based coping, social support seeking, emotional relaxation coping, and hopeful thinking coping. Problemsolving and social support seeking coping are classified as active coping, emotional-oriented coping and hopeful thinking coping as passive coping.

As a result of this study, firefighters were more likely to use passive coping $(43.60 \pm 5.86)$ than active coping (41.34 \pm 7.04), which is a result of previous research studying coping methods of firefighters in Korea [8]. In this study, Korean people traditionally use the method of adjusting their minds, but firefighters seem to be making passive coping with the difficulty of constantly fixing and solving sudden events in a difficult work environment. In another study, firefighting officers used active coping and passive coping together, but it is reported that the subjects who use passive coping methods such as emotional-centered coping style have negative effects on mental health such as post-traumatic stress disorder [9].

The resilience of firefighting officers was not statistically significant in general characteristics such as sex, age, educational background, religion, etc, except subjective health status. A previous study found that resilience has the effect of controlling job stress and depression showed that the resilience of firefighters was not significant in gender, religion, or marriage, but the results showed that the resilience of those who graduated from college or higher was higher than that of those who graduated from high school or below [24]. A study of the relationship between resilience and post-traumatic stress disorder in firefighters found that resilience significantly affected PTSD (post-traumatic stress disorder) and that resilience was not affected by demographic variables, which means that the resilience level of firefighters was low [25]. 
$84.4 \%$ of the respondents said they did not feel that they needed help in counselling and treatment. However, the actual experience of counselling by firefighters is noted for resilience and reports that counselling experience helps improve resilience [25]. In the present study, the resilience of the subjects was positively correlated with stress coping $(\mathrm{r}=0.666$, $\mathrm{p}<0.001)$ and the subcategories of stress coping $(\mathrm{r}=0.774$, $\mathrm{p}<0.001)$, passive coping $(\mathrm{r}=0.429, \mathrm{p}<0.001)$. The factors affecting resilience were stress coping and subjective health status. It is urgent to find ways to improve the resilience of firefighting officers because the decrease of resilience may lead to mental health problems.

\section{Conclusion}

This study has tried to identify the relationship between stress coping and resilience of firefighters, to identify factors affecting resilience and to cope with stress, and to make a basic data to improve the mental health of firefighters.

Based on the results of this study, the following suggestions are made. First, it is necessary to study stress management programs, including counselling, for firefighters who have to face sudden and difficult situations continuously. Second, research on the development and application of arbitration programs that increase the active coping method is needed to improve the mental health of firefighting officers. Third, research is needed to develop and apply programs that can improve the resilience of firefighters.

\section{Conflict of Interest}

The authors report no conflicts of interest related to this study. The author does not have any financial interest in the companies whose materials are included in the article.

\section{References}

1. Kim ST. The relationship between the restriction on leisure, lifestyle and the quality of life on police and a firefighting officer who is participated in leisure activity. Yongin University Doctoral Thesis 2012; 1-127.

2. El Sayed M, El Tawil C, Tamim H, Mailhac A, Mann NC. Emergency medical services experience with barb removal after taser use by law enforcement: a descriptive national study. Prehosp Disaster Med 2018.

3. Yean JG A study on traumatic stress in fire fighters. Seoul City University Masters Thesis 2001; 1-103.

4. Lazalus RS, Folkman S. Stress, appraisal and coping. New York: Springer 1984; 1-215.

5. Silver R. Wortman CB. Coping with undersirable life events. New York: Academic Press 1980.

6. Kim HJ. The study on the work stress and coping methods of the nurses in Intensive Care Unit. Hanyang University Masters Thesis 2006; 1-65.

7. Kim JH. A study on the relationships between personality characteristics of children by stress level and stress coping style. Kangwon National University Masters Thesis 1995; $1-55$.

8. Kim BM, Pan SH, Chae JH. Relationship between posttraumatic stress, coping style, and dissociation in Korean firefighters. Anxiety Mood 2011; 7: 29-33.

9. Lee HJ, Kim HS, Park SY. Effects of perception of job stress and stress coping style on mental health of firefighters. J Korean Acad Psychiatr Ment Health Nurs 2011; 20: 315-324.

10. Walsh F. The resilience of the field of family therapy. J Marital Fam Ther 1998; 24: 269-271.

11. Bonanno GA. Resilience in the face of potential trauma. Curr Direct Psychol Sci 2005; 14: 135-138.

12. Ong AD, Bergemanm CS, Bisconti TL, Wallace KA. Psychological resilience, positive emotions, and successful adaptation to stress in later life. J Personal Soc Psychol 2006; 91: 730-749.

13. Go YM. The relationships among mothers the parenting stress, recovery resilience, self contral in preschool children. Kyungwon University Masters thesis 2010; $1-52$.

14. Kim JS. The effects of psychodrama on the resilience of the middle-aged women. Wonkwang University Masters Thesis 2012; 1-71.

15. Kim HE. The predictive effect of job stress and resilience on burnout with social-welfare officials. Jeju University Masters Thesis 2014; 1-66.

16. Kim JH, Lee JH. The relationship between constructive factors of stress coping methods and depression. Behav Sci Res 1985; 7: 127-138.

17. Bang YM. The role of stress coping style in the relationship between perfectionism and academic exhaustion. Korea University Masters Thesis 2016; 1-49.

18. Lee KH, Lee SW. Concept analysis of resilience. Korean J Stress Res 2005; 13: 9-18.

19. Baek HS. Reliability and validity of the Korean version of the Connor-Davidson Resilience Scale (K-CD-RISC). Ewha Womans University Masters Thesis 2010; 1-30

20. Connor KM, Davidson, JRT. Development of a new resilience scale: the Connor-Davidson resilience scale (CD-RISC). Depression Anxiety 2003; 18: 76-82.

21. Park EJ, Kim KE, Baek HS, Yu JC/, Choi KS. The effect of positive psychological characteristics on post-traumatic stress symptoms after traumatic experiences in firefighters. J Korean Neuropsych Assoc 2010; 49: 645-652.

22. Kang BW. A study on the relationship between job stress and socio-psychological stress of firefighter. J Korean Soc Emerg Med Technol 2009; 13: 35-48.

23. Lee HE, Kang SH, Ye BS, Choi JH. The effect of resilience on posttraumatic stress disorder symptoms and comorbid symptoms in firefighters. Anxiety Mood 2012; 8: 86-92.

24. Choi HC. The effect of the resilience on firefighters job stress and depression relations. Korean J Soc Welfare Educ 2013; 23: 69-91. 
25. Song YS. The relationship between fire-fighters resilience and PTSD. Fire Sci Eng 2017; 31: 119-126.

\section{*Correspondence to}

Young-Soon Choi

Department of Nursing

College of Health Sciences

Kangwon National University

Republic of Korea 